\title{
Efeito do tratamento com Casearia Sylvestris sobre a angiogênese induzida pelas células tumorais de Ehrlich
}

\author{
Effect of treatment with Casearia Sylvestris on angiogenesis induced by Ehrlich tumor \\ cells
}

Efecto del tratamiento con Casearia Sylvestris sobre la angiogénesis inducida por células tumorales de Ehrlich

Monique Malta Francese $^{1 *}$, Ádrika Maria Andrade Christianini ${ }^{1}$, Paulo Henrique Weckwerth ${ }^{1}$

\section{RESUMO}

Objetivo: Avaliar a interferência do tratamento com extrato de Casearia Sylvestris Sw. sobre a angiogênese induzida por células tumorais de Erhlich. Métodos: Utilizou-se 28 ovos embrionados aleatoriamente distribuídos em quatro grupos de ovos ( $n=7 / g r u p o)$, sendo eles: Grupo 1 - Soro fisiológico; Grupo 2 - Tumor de Ehrlich (TE); Grupo 3 - Casearia Sylvestris Sw. - Grupo 4: Casearia Sylvestris Sw + Tumor de Ehrlich. Os ovos foram submetidos à incubação durante 48 horas; sendo sujeitados ao tratamento decorridas 24 horas iniciais de incubação. Resultados: $\mathrm{O}$ tipo de tratamento aplicado em cada grupo interferiu individualmente nos resultados, onde relatou-se: Grupo 1- Padrão normal de crescimento (grupo controle); Grupo 2 - Aumento na proliferação de vasos sanguíneos; Grupo 3 - Baixa interferência no efeito do tratamento; Grupo 4 Ramificações de vasos sanguíneos menos evidentes. Conclusão: Considera-se através dessa técnica a possibilidade da utilização do extrato de Casearia Sylvestris Sw. para o tratamento de células tumorais de Ehrlich, pela eficácia da planta contra proliferação de células malignas, entretanto devem ser realizados testes confirmatórios para confirmar quais propriedades da mesma são responsáveis por tal efeito.

Palavras-chave: Embrião de galinha, Fitoterapia, Neoplasia, Tratamento farmacológico.

\begin{abstract}
Objective: To evaluate the interference of treatment with Casearia Sylvestris Sw. Extract on angiogenesis induced by Erhlich tumor cells. Methods: Twenty-eight embryonic eggs were randomly distributed in four groups of eggs ( $n=7$ / group), namely: Group 1 - Saline; Group 2 - Ehrlich's tumor (ET); Group 3 - Casearia Sylvestris Sw. - Group 4: Casearia Sylvestris Sw. + Ehrlich Tumor. The eggs were incubated for 48 hours; undergo treatment after the first 24 hours of incubation. Results: The type of treatment applied in each group interfered individually in the results, where it was reported: Group 1- Normal growth pattern (control group); Group 2 - Increased proliferation of blood vessels; Group 3 - Low interference in the treatment effect; Group 4 - Branches of less evident blood vessels. Conclusion: The possibility of using Casearia Sylvestris Sw. is considered through this technique. Extract for the treatment of Ehrlich tumor cells, due to the plant's effectiveness against the proliferation of malignant cells, however confirmatory tests must be performed to confirm which properties of the they are responsible for such an effect.
\end{abstract}

Keywords: Chicken embryo, Phytotherapy, Neoplasia, Pharmacological treatment.

\section{RESUMEN}

Objetivo: Evaluar la interferencia del tratamiento con el extracto de Casearia Sylvestris Sw. Sobre la angiogénesis inducida por células tumorales de Erhlich. Métodos: Se distribuyeron aleatoriamente veintiocho huevos embrionarios en cuatro grupos de huevos ( $n=7$ / grupo), a saber: Grupo 1 - Solución salina; Grupo 2: tumor de Ehrlich (ET); Grupo 3 - Casearia Sylvestris Sw. - Grupo 4: Casearia Sylvestris Sw. + Tumor de Ehrlich. Los huevos se incubaron durante 48 horas; someterse a tratamiento después de las primeras 24

${ }^{1}$ Unisagrado, Bauru - SP. *E-mail: monique.francese@gmail.com 
horas de incubación. Resultados: El tipo de tratamiento aplicado en cada grupo interfirió individualmente en los resultados, donde se informó: Grupo 1- Patrón de crecimiento normal (grupo control); Grupo 2: aumento de la proliferación de vasos sanguíneos; Grupo 3 - Baja interferencia en el efecto del tratamiento; Grupo 4: Ramas de vasos sanguíneos menos evidentes. Conclusión: Se considera la posibilidad de utilizar Casearia Sylvestris Sw. mediante esta técnica. Extracto para el tratamiento de células tumorales de Ehrlich, debido a la efectividad de la planta frente a la proliferación de células malignas, sin embargo se deben realizar pruebas confirmatorias para confirmar qué propiedades del ellos son responsables de tal efecto.

Palabras clave: Embrión de pollo, Fitoterapia, Neoplasia, Tratamiento farmacológico.

\section{INTRODUÇÃO}

Segundo a American Cancer Society, uma sociedade que estima o número de novos casos de câncer e mortes que ocorrerão nos Estados Unidos, em 2020 projetou-se que ocorrerão1.806.590 novos casos de câncer e 606.520 mortes por câncer em 2020, sendo este um importante problema de saúde pública e a segunda causa de morte nos Estados Unidos (SIEGEL RL, et al., 2020).

Dentre os principais tratamentos, inclui-se a quimioterapia que utiliza medicamentos anti-neoplásicos para destruir as células tumorais e a radioterapia que consiste na utilização de feixes ionizantes para a destruição de tecidos tumorais malignos (LEITE FMC, et al., 2011; SILVA APA, et al., 2019).

Apesar dos avanços significativos na tecnologia médica para o diagnóstico e tratamento de câncer, os pacientes geralmente não lidam bem com essas terapias que além de produzir efeitos colaterais (dor, fadiga, comprometimento funcional, morbidade e transtornos psicológicos) ou reações tóxicas, apresentam alto custo (CEYLAN D, et al., 2018; FRENSHAM LJ, et al., 2018; SILVA APA, et al., 2019).

As células cancerosas continuam a se multiplicar, a menos que ocorra um dos quatro eventos: A massa cancerosa é removida cirurgicamente; a radioterapia é utilizada; as células cancerosas encolhem e desaparecem por conta própria; e utiliza-se quimioterapia ou outro tipo de medicamento específico para o câncer, como terapia hormonal (ROY OS, et al., 2016).

O presente estudo trata-se da contribuição ao tratamento do câncer, através da ocorrência do último evento. Sabe-se que existe uma ampla variedade de plantas com propriedades medicinais, incluindo cerca de 70.000 espécies de plantas usadas ao decorrer das épocas para fins medicinais (PAN SY, et al., 2013).

Dentre essas plantas, podemos citar a Casearia sylvestris (C. sylvestris), que se distribui nas regiões tropicais e subtropicais do Brasil e em outros países da América do Sul e Ásia. Esta possui grande importância na área de farmacologia por suas propriedades anti-imflamatórias, antiplasmódicas e antiúlcera. A guaçatonga, como é denominada popularmente, faz parte do uso tradicional no Brasil, além de ter seu nome citado na "Lista Nacional de Plantas Medicinais de Interesse do SUS", o qual contém 71 espécies de plantas com alta incidência de cura para doenças. Tribos indígenas também utilizam a casca macerada de $C$. sylvestris para tratar distúrbios gastrointestinais, picadas de cobra e para curas feridas, enquanto que a casca é utilizada como um anti-inflamatório (RIBEIRO SM, et al., 2019).

Fitoquimicamente, o gênero Casearia caracteriza-se pela ocorrência de metabólitos biologicamente ativos. Foi descrita uma classe de compostos que exibem atividade antitumoral e importantes atividades antineoplásicas. O estudo de plantas com metabólitos que proporcionam atividade antitumoral pode fornecer informações importantes para o desenvolvimento de novos medicamentos, graças aos diterpenóides presentes na mesma (BOU DD, et al., 2013). Em um estudo realizado por Bou DD, et al. (2013) o óleo essencial bruto das folhas de $C$. sylvestris, foi ativo contra todas as linhagens de células tumorais testadas, sugerindo que este pode ser um interessante agente para o tratamento do câncer e consequentemente para o estudo da angiogênese.

Desta forma, pode-se dizer que o mecanismo de desenvolvimento do câncer está fortemente relacionado a um aumento no número de células e alterações nos mecanismos que regulam a proliferação celular. Porém essas duas alterações são apenas uma das facetas dos mecanismos do câncer. A diminuição da taxa de 
morte celular ou apoptose também podem contribuir para certos tipos de câncer, já que essa patologia é caracterizada pela capacidade de invadir os tecidos circundantes, tratando-se de mutações genéticas que desregulam as atividades dos genes, controlam o crescimento celular, regulam a sensibilidade à morte celular programada e mantêm a estabilidade genética (DONEPUDI MS, et al., 2014). A angiogênese é como se denomina a formação de novos vasos sanguíneos, a partir de vasos sanguíneos pré existentes por meio do processo de germinação, sendo considerado uma das mais importantes marcas do câncer.

A angiogênese pode tanto ocorrer em condições fisiológicas, durante o desenvolvimento embrionário, quanto durante a cicatrização de feridas em adultos. Na progressão do câncer, a angiogênese patológica é impulsionada por meio da superexpressão de fatores pró-angiogênicos, criando um desequilíbrio entre próangiogênicos e antiangiogênicos, gerando um novo suprimento vascular. Diferentemente da cicatrização de feridas, onde a angiogênese passa por uma fase de resolução, a angiogênese do tumor continua com um crescimento desordenado de células cancerosas, já que elas requerem suprimento vascular para fornecer os nutrientes e oxigênio necessários para proliferação (RAMJIAWAN RR, et al., 2017).

O tumor de Ehrlich (TE) é um adenocarcinoma mamário de camundongo que pode se desenvolver nas formas sólida e ascítica, dependendo da administração do mesmo, em tecidos e cavidades respectivamente. A forma ascítica do tumor, tem sido amplamente empregada como modelo experimental para avaliar a influência de substâncias de diferentes origens em sua proliferação ou resposta do hospedeiro associada a presença de células tumorais (CALIXTO-CAMPOS C, et al., 2013).

O câncer de mama geralmente é geralmente diagnosticado através do rastreamento de um sintoma, que pode ser dor ou massa palpável nas mamas, levando a um exame diagnóstico. Ainda assim, a única modalidade de rastreamento comprovada para reduzir a mortalidade específica por câncer de mama, é a mamografia (MCDONALD ES, et al., 2016).

O conhecimento sobre o desenvolvimento do tumor levou ao estudo de substâncias anti-angiogênicas para interromper o suprimento vascular e privar o tumor de nutrientes e oxigênio. Dado o sucesso de pesquisas envolvendo substâncias anti-angiogênicas, o preparo de soluções obtidas a partir de plantas medicinais tornaram-se uma estratégia atraente (RAMJIAWAN RR, et al., 2017). Considerando os estudos que utilizam a característica anti-angiogênica de substâncias naturais para interromper o suprimento vascular e privar o tumor de nutrientes e oxigênios, o objetivo deste trabalho é avaliar a interferência do tratamento com Casearia sylvestris na angiogênese relacionada ao crescimento de células tumorais de Ehrlich em modelo da membrana corioalantóide (MAC).

\section{MÉTODOS}

O estudo realizado foi de natureza explanatória, a partir da hipótese de que a angiogênese relacionada ao crescimento tumoral é afetada pelo tratamento com o extrato das folhas de Casearia Sylvestris Sw. Os dados obtidos através do estudo foram analisados por meio de uma metodologia qualitativa.

Os procedimentos serão descritos a seguir. O modelo experimental utilizado foi à membrana corioalantóide. Essa membrana, considerada como o pulmão do embrião, é uma estrutura fina ( $<100 \mu m)$ que se expande rapidamente, formando uma rede vascular rica que favorece a troca de gases e resíduos durante o desenvolvimento das aves.

A MAC permite estudar enxertos de tecido, crescimento tumoral, metástases, administração de drogas, análises toxicológicas e substâncias angiogênicas e antiangiogênicas, além de ser uma técnica simples, rápida e de baixo custo (DERYUGINA EI e QUIGLEY JP, 2008; RIBATTI D, 2017).

Empregaram-se células tumorais do Tumor Ascítico de Ehrlich, fornecidas através de doação dos responsáveis pelo laboratório de pâncreas endócrino da Universidade Estadual Paulista (UNESP) de BauruSP. Após o recebimento de uma alíquota de $500 \mu \mathrm{L}$ de fluido acético, utilizou-se uma câmara de Neubauer e microscópio óptico para a contagem celular da solução. 
A contagem de células foi realizada manualmente através do contador de células, por duas pessoas diferentes e os valores obtidosindividualmente foram somados obtendo-se a média de células tumorais. Após obter a concentração da solução, realizou-se ainda uma diluição em solução salina fisiológica estéril para preparo de uma suspensão contendo $10^{6}$ células tumorais por $\mathrm{mL}$ (CEYLAN D, et al., 2018). Após seu preparo, a solução foi imediatamente inoculada nos ovos. Para o preparo do extrato aquoso, optou-se pelo processo de infusão. Desta forma, $15 \mathrm{~mL}$ de água destilada foram aquecidos no forno micro-ondas. Após a fervura da água, adicionou-se $1 \mathrm{~g}$ da Guaçatonga em pó e a solução permaneceu em repouso durante 10 minutos.

Após o tempo estimado, o extrato foi filtrado e armazenado em um frasco de vidro dentro da geladeira, até o momento do uso. Utilizou-se o extrato de $C$. Sylvestris nomesmo dia do seu preparo (GÜNTZEL ARC, 2008). Empregou-se 28 ovos fertilizados de galinha da espécie Gallus domesticus, da raça Índio grande. No primeiro dia de procedimento, os ovos foram inicialmente higienizados com álcool 70\% e distribuídos aleatoriamente em seus respectivos grupos. Os ovos foram incubados na chocadeira na temperatura de $37,5^{\circ} \mathrm{C}$, a uma umidade em torno de 60 a 70\%, durante 24 horas. A acomodação dos ovos foi feita através de fileiras verticais com no máximo 5 ovos, facilitando a movimentação mecânica do equipamento (FRANCESE MM e WECKWERTH, 2020).

No segundo dia de incubação, executou-se uma abertura de aproximadamente $0,3 \mathrm{~cm}$ de diâmetro com o auxílio de uma agulha de insulina $13 \times 4,5$ na base maior de cada ovo. As soluções de interesse foram inoculadas através da abertura realizada nos ovos onde foram inseridas líquotas de 100ul em cada ovo: Grupo 1: Soro fisiológico (100ul); Grupo 2: Tumor de Ehrlich (100ul); Grupo 3: Casearia Sylvestris Sw. (100ul); Grupo 4: Casearia Sylvestris Sw. (50ul) + Tumor de Ehrlich (50ul). Após o tratamento a abertura foi vedada com parafina líquida. As amostras tratadas foram realocadas na incubadora durante 24 horas, obtendo-se as 48 horas de desenvolvimento necessárias para o estudo de vascularização da membrana. Ao término da incubação, os ovos foram retirados para a remoção das membranas corioalantóide (MCAs).

Antes de serem abertos, os mesmos permaneceram em repouso em temperatura ambiente durante 10 minutos em posição horizontal. Os ovos foram quebrados individualmente e seus conteúdos inseridos em uma placa Petri contendo água. Cortaram-se as laterais da gema com tesoura cirúrgica e deslocou-se a membrana com uma espátula de ponta reta. Após serem removidas, as membranas foram depositadas em outra placa Petri contendo solução formol 37\% onde permaneceram durante 24 horas e o conteúdo restante dos ovos foi descartado na pia.

A solução formol foi utilizada como solução fixadora (SILVEIRA SO, 2013). Seguido a fixação, conservouse as membranas em frascos estéreis contendo álcool, não ultrapassando 7 dias de conservação, evitando endurecimento da MCA. No dia previsto para análise, as membranas foram retiradas cuidadosamente dos frascos e adicionadas em um Becker com água. Com um auxílio de pincel, as membranas foram aderidas em lâminas para microscopia e distendidas para melhor visualização. Finalmente, obteve-se fotografias a partir da câmera do Smartphone Asus Zenfone 5 Selfie Pro, que registrou as imagens aumentadas através do estereoscópio lupa binocular.

As fotografias foram tratadas através do software Adobe Photoshop CS6 versão 13.0, através das seguintes ferramentas: Brilho/contraste, saturação, vibração e filtro de inversão. O modelo experimental optado pelos autores, não exige procedimentos administrativos para obter aprovação do comitê de Ética em Pesquisa (CEP) para experimentação animal (RIBATTI D, 2017), por se tratar de um modelo que utiliza apenas ovos embrionados, até seu quarto dia de desenvolvimento, na ausência de sistema nervoso.

\section{RESULTADOS}

O "Grupo 1 - Soro fisiológico (100ul)" corresponde ao grupo controle negativo do estudo, onde o mesmo foi empregado como parâmetro de comparação. Na superfície da membrana, relatou-se um padrão normal de desenvolvimento dos vasos sanguíneos do embrião de galinha (considerando quantidade e aspecto dos 
vasos), dentro dos padrões de crescimento de uma ave. Isto deve-se ao fato do grupo não ter recebido nenhum tipo de tratamento que pudesse interferisse no processo. A administração de 100ul de soro fisiológico nos ovos desse grupo, tiveram como o objetivo apenas padronizar a concentração de substâncias dos ovos.

O grupo controle negativo foi utilizado como parâmetro de comparação ou grupo controle, onde os resultados obtidos próximos a ele foram considerados normais, e os diferentes foram considerados anormais, divididos em crescimento aumentado ou diminuído de vasos sanguíneos. No total de 7 ovos incubados, foi possível executar a remoção da membrana corioalontóide de 4 ovos (Figura 1).

O "Grupo 2: Tumor de Ehrlich (100ul)" apresentou aceleração no desenvolvimento embrionário e quanto a produção de vasos sanguíneos em sua superfície embrionária, onde esta apresentou ramificações mais evidenciadas. Ainda observou-se que as membranas removidas foram caracterizadas pela presença de pontos hemorrágicos por toda sua extensão, indicando que o tumor instalado produziu uma vascularização própria e disfuncional. No total de 7 ovos incubados, foi possível remover a membrana corioalantóide de 3 ovos (Figura 1).

Já o "Grupo 3: Casearia Sylvestris Sw. (100 ul)" apresentou diminuição no desenvolvimento embrionário e quanto a produção de vasos sanguíneos, estes apresentaram ramificações semelhantes a de uma desenvolvimento normal. A literatura demonstra que a Casearia Sylvestris Sw. possui propriedades capazes de favorecer a angiogênese e por consequência a cicatrização. No total de 7 ovos incubados, foi possível remover a membrana corioalantóide de 2 ovos (Figura 1).

Por fim, o "Grupo 4: Casearia Sylvestris Sw. (50ul) + Tumor de ehrlich (50ul)" apresentou diminuição no desenvolvimento embrionário e quanto a produção de vasos sanguíneos, estes apresentaram ramificações menos evidentes, indicando que a Casearia Sylvestris Sw. interfere na angiogênese quando associada ao Tumor de Ehrlich. No total de 7 ovos incubados, foi possível remover a MCA de 2 ovos.

Pode-se observar a fotografia original e em seguida, a fotografia submetida aos ajustes no Photoshop, onde foram destacadas as delimitações em amarelo, indicando os principais vasos sanguíneos desenvolvidos, e em vermelho, os limites do embrião (Figura 1).

No "Grupo 4: Casearia Sylvestris Sw. (50ul) + Tumor de ehrlich (50ul)" não foi possível delimitar os vasos sanguíneos, pois os mesmos encontraram-se em escassez.

Figura 1 - Aspecto microscópico da MCA dos ovos controles pertencentes aos diferentes grupos após 48 horas de incubação.

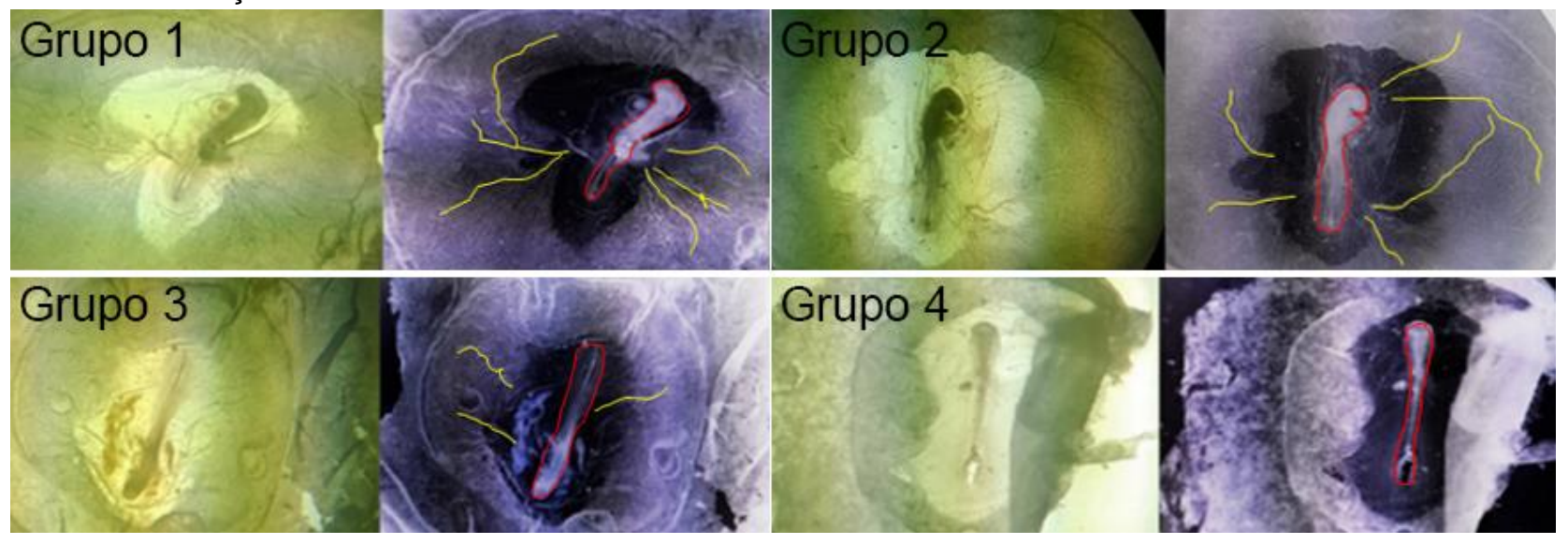

Fonte: Francese MM, et al., 2020.

A remoção das membranas não foi possível em todos os ovos incubados e isto deve-se a fatores comuns ao desenvolvimento natural, onde não há garantia de que todos os ovos manuseados tratava-se de ovos embrionados, em consequência da condições naturais de temperatura, umidade, manuseio e época. 
Outro fator que pode ter interferido no sucesso de desenvolvimento embrionário é a movimentação mecânica, pois tratando-se de uma incubadora automática, nem todos os ovos adicionados à chocadeira receberam adequadamente a força necessária para evitar que a membrana ficasse aderida a casca do ovo, provocando seu rompimento e perda da amostra. Conforme demonstra o Gráfico 1, as porcentagens de membranas corioalantoidea extraídas na ordem dos grupos, foram $57,14 \%$ (grupo 1), 42,85\% (grupo 2), $28,57 \%$ (grupo 3) e $28,57 \%$ (Grupo 4).

Gráfico 1 - Comparação de membranas removidas em relação ao total de ovos incubados

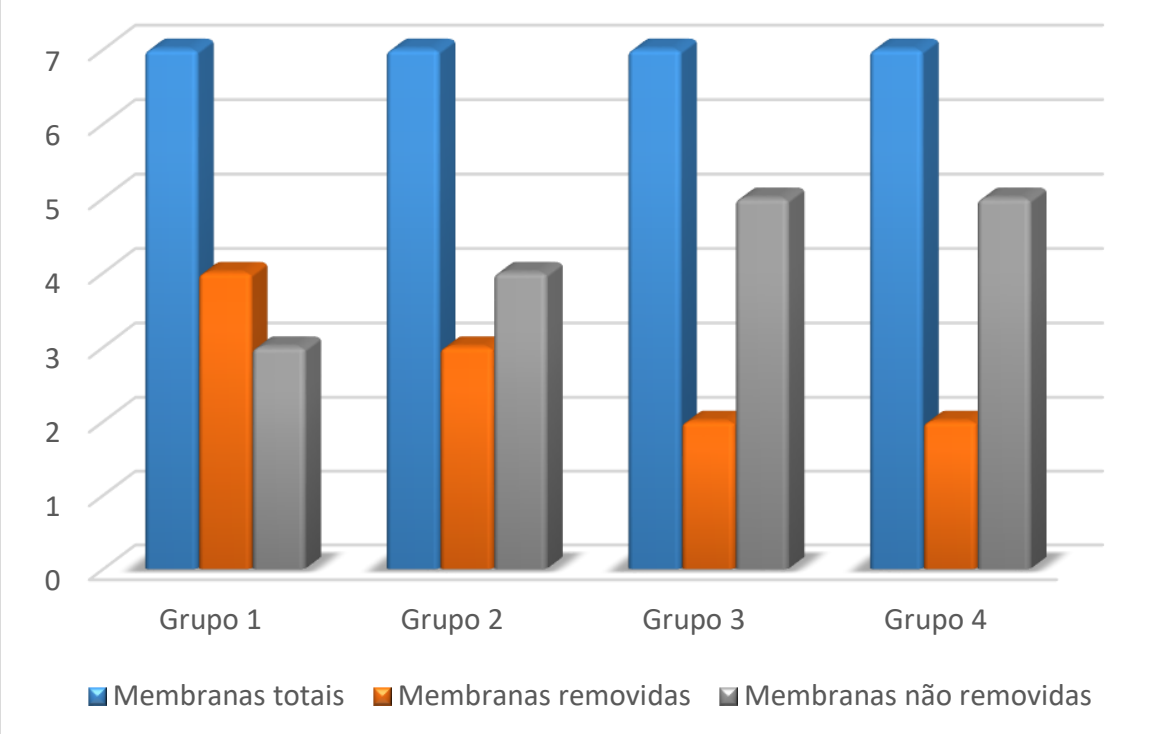

Fonte: Francese MM, et al., 2020.

\section{DISCUSSÃO}

O tratamento com soro fisiológico utilizado no primeiro grupo embasou-se no artigo científico realizado pelo autor Chaves DA et al. (2016), onde 56 ovos foram tratados com uma gota de soro fisiológico no quinto dia de incubação. Porém para este trabalho, adotaram-se apenas 48 horas de incubação, por concluir-se que este tempo é o suficiente para pesquisa da neovascularização da MCA.

Segundo autores consultados, a presença de um tecido ou célula tumoral (como por exemplo células TE) favorece a liberação de enzimas e proteínas que podem desencadear a angiogênese, favorecendo a formação de novos vasos para alimentar o tumor, evento este que pode ser observado no segundo grupo através dos pontos de hemorragia (PINHO MSL, 2005).

Este processo permaneceria enquanto o ovo permanecesse incubado, favorecendo a formação de novos vasos e podendo levar a alterações morfológicas e morte embrionária (LABNETWORK, 2015). Apesar da Casearia Sylvestris Sw. favorecer a angiogênese, no experimento do grupo 3 não houve interferência na quantidade de vasos formados no embrião de galinha, fato este que se justifica pela ausência de células tumorais de Ehrlich, já que não houve estímulo para que as substâncias ativas da planta interferissem no processo. Por outro lado, observa-se que o resultado do tratamento do grupo 4 confirma que a Casearia Sylvestris Sw. possui propriedades antitumorais. As mesmas foram estudadas por outros autores e caracterizadas de acordo com seu potencial de ação (FELIPE K, 2014).

Um estudo realizado demonstrou que a fração "casearina C" apresentou maior eficácia em seu efeito antitumoral (FELIPE K, 2014), podendo ser a responsável, pois, por tais efeitos observados no estudo. A facilidade e acessibilidade da MCA são indiscutíveis. Estudos que objetivam avaliar o efeito do tratamento de 
substâncias em associação com células tumorais têm aproveitado este modelo capaz de fornecer os 3 Rs da sustentabilidade (reduzir, reutilizar e reciclar), que são ações realizadas com 0 intuito de minimizar 0 desperdício de materiais e produtos, além de poupar a natureza da extração abusiva de recursos (ARAúJO A, et al., 2017).

Adotando estas práticas, é possível impactar na forma com que animais são utilizados na pesquisa, permitindo a redução de gastos pertinentes à prática experimental consequente a redução do tempo de tratamento. Curiosamente, os investigadores relataram a possibilidade na redução do tempo de incubação dos ovos, através de testes preliminares feitos apenas com ovos embrionados. Apesar dos ótimos resultados obtidos através da utilização do extrato de Casearia Sylvestris Sw. em estudos tumorais, faz-se necessário promover a separação de cada uma das frações da Casearia Sylvestris Sw. para a ciência de qual fração de fato está associada a esses efeitos.

Outro ponto a ser questionado é se essa associação entre células tumorais de Ehrlich e extrato de guaçatonga poderiam causar alterações irreversíveis no embrião em desenvolvimento ou até mesmo sua morte. Compreende-se que a técnica em questão, pode não reproduzir o funcionamento humano em sua totalidade, sendo necessário a associação de outras técnicas que garantam seus resultados positivos. Além disso, por ser uma técnica ainda pouco empregada, relatam-se dificuldades ao que diz respeito às condições necessárias para o desenvolvimento embrionário, como por exemplo o tempo de incubação, não muito bem definido na literatura, sendo encontradas discrepâncias.

No mais, acrescentamos que pesquisas científicas nesta área tem muito que acrescentar na promoção da ciência e na melhoria da qualidade de vida das pessoas. Quanto ao uso de animais em pesquisas, esta técnica pode fornecer uma válvula de escape aos pesquisadores, permitindo a eliminação do uso de seres vivos em pesquisas, dependendo da análise de interesse, ou também a redução da quantidade, podendo oferecer um estudo prévio. Não foram encontrados estudos envolvendo atividade angiogênica de Guaçatonga e TE, através do modelo experimental utilizando ovos embrionados, seguindo os parâmetros utilizados nesta pesquisa, em específico. Desta forma, este estudo poderá fornecer subsídio para pesquisas futuras, tendo em vista o interesse dos pesquisadores em plantas medicinais nos últimos anos.

\section{CONCLUSÃO}

Através do presente estudo científico, pode-se observar a influência que algumas substâncias possuem sobre neovascularização, dependendo do tipo de solução administrada, inferindo a existência de propriedades na Casearia Sylvestris Sw. que influenciam positivamente no desenvolvimento embrionário aviário e negativamente no desenvolvimento da angiogênese tumoral. Diante das descobertas apresentadas, antes de considerar a utilização de Casearia Sylvestris Sw. para fins medicinais visando o tratamento de tumores malignos, faz-se necessário a realização de mais estudos envolvendo o modelo da MCA, averiguando a reprodutibilidade do mesmo, e também a utilização de outras metodologias que possam confirmar os resultados obtidos.

\section{AGRADECIMENTOS E FINANCIAMENTO}

Agradecemos à Prof ${ }^{\underline{a}}$ Dra. Dulce Helena Jardim Constantino, por dar início à construção deste projeto. Os autores declaram que todos os custos e investimentos pertinentes a pesquisa foram bancados por eles próprios.

\section{REFERÊNCIAS}

1. ARAÚJO A, et al. Projeto de horta orgânica para uma unidade escolar da rede pública de ensino do município do Rio de Janeiro. Revista Presença, 2017; 3(8): 1-12.

2. BOU DD, et al. Chemical composition and cytotoxicity evaluation of essential oil from leaves of Casearia sylvestris, its main compound $\alpha$-zingiberene and derivatives. Molecules, 2013;18(8):9477-9487. 
3. CALIXTO-CAMPOS C, et al. The Ehrlich tumor induces pain-like behavior in mice: a novel model of cancer pain for pathophysiological studies and pharmacological screening. Biomed Res Int., 2013.

4. CEYLAN D, et al. The effects of gilaburu (Viburnum opulus) juice on experimentally induced Ehrlich ascites tumor in mice. J Cancer Res Ther., 2018; 14(2):314-320.

5. CONSELHO REGIONAL DE FARMÁCIA - Resolução RDC 354.

6. DERYUGINA EI, QUIGLEY JP. Chick embryo chorioallantoic membrane model systems to study and visualize human tumor cell metastasis. Histochem Cell Biol., 2008; 130(6):1119-1130.

7. DONEPUDI MS, et al. Breast cancer statistics and markers. J Cancer Res Ther., 2014; 10(3):506-11

8. FELIPE K. Estudo do mecanismo de ação antiproliferativa e antitumoral de extratos de Casearia Sylvestris e de fenilaminonaftoquinonas associadas ou não ao ascorbato de sódio. Dissertação (Pós Graduação em Bioquímica) Universidade Federal de Santa Catarina, Florianópolis 2014.

9. FERREIRA PMP, et al. Folk uses and pharmacological properties of Casearia sylvestris: a medicinal review. An Acad Bras Ciênc., 2011; 83(4):1373-1384.

10. FRANCESE MM, WECKWERTH PH. Análise do efeito do tratamento com nanopartículas de prata (AgNO3) revestidas com pectina sobre a angiogênese induzida pelas células do tumor de ehrlich em modelo da membrana corioalantoidea. SalusVita, 2020; 39(1): 23-42

11. FRENSHAM LJ, et al. Effect of a 12-Week Online Walking Intervention on Health and Quality of Life in Cancer Survivors: A Quase-Randomized Controlled Trial, Switzerland. International Journal of Environmental Research and Public Health, 2018, 15: 1-17.

12. GÜNTZEL ARC. Avaliação das atividades farmacológicas de extratos de Casearia Sylvestris Sw. Dissertação (Mestrado em farmacologia) - Universidade do Vale do Taquari, Rio Grande do Sul, 2008; 68 p.

13. LABNETWORK. A revolução de um método de pesquisa alternativo ao uso de animais. 2015.

14. LEITE FMC, et al. Mulheres com Diagnóstico de Câncer de Mama em Tratamento com Tamoxifeno: Perfil Sociodemográfico e Clínico, Espírito Santo. Revista Brasileira de Cancerologia, 2011; 57:15-21.

15. MCDONALD ES, et al. Clinical Diagnosis and Management of Breast Cancer. J Nucl Med., 2016; 1:9-16.

16. PAN SY, et al. Historical perspective of traditional indigenous medical practices: the current renaissance and conservation of herbal resources. Evid. Based Complement. Alternat. Med., 2013; 1-20.

17. PINHO MSL. Angiogênese: o gatilho proliferativo. Seção de genética e biologia molecular do departamento de medicina da Univille, Joinville, 2005; 396-402.

18. RAMJIAWAN RR, et al. Anti-angiogenesis for cancer revisited: Is there a role for combinations with immunotherapy?. Angiogenesis, 2017;20(2):185-204.

19. RIBATTI D. The chick embryo chorioallantoic membrane (CAM) assay. Reprod Toxicol., 2017; 70:97-101.

20. RIBEIRO SM, et al. Antimicrobial and antibiofilm activities of Casearia sylvestris extracts from distinct Brazilian biomes against Streptococcus mutans and Candida albicans. BMC Complement Altern Med., 2019;19(1):308.

21. ROY PS, SAIKIA BJ. Cancer and cure: A critical analysis. Indian J Cancer, 2016; 53(3):441-442.

22. SIEGEL RL, et al. Cancer statistics. CA Cancer J Clin., 2020; 70(1):7-30.

23. SILVA APA, et al. A influência do exercício físico na qualidade de vida de adultos sobreviventes de câncer. Revista Eletrônica Acervo Saúde, 2019; 34:e1501.

24. SILVEIRA SO. Orientação para práticas de Laboratório. 2015; 5(2): 234-248. 